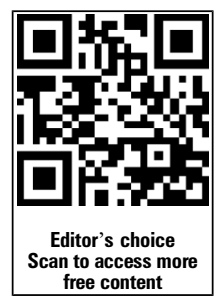

\title{
How safe is primary care? A systematic review
}

\author{
Sukhmeet Singh Panesar, ${ }^{1}$ Debra deSilva, ${ }^{2}$ Andrew Carson-Stevens, ${ }^{3}$ \\ Kathrin M Cresswell, ${ }^{4}$ Sarah Angostora Salvilla, ${ }^{4}$ Sarah Patricia Slight, ${ }^{5}$ \\ Sundas Javad, ${ }^{6}$ Gopalakrishnan Netuveli, ${ }^{7}$ Itziar Larizgoitia, ${ }^{8}$ \\ Liam J Donaldson, ${ }^{9}$ David W Bates, ${ }^{10}$ Aziz Sheikh ${ }^{4}$
}

\begin{abstract}
- Additional material is published online only. To view please visit the journal online (http://dx.doi.org/10.1136/bmjqs2015-004178)

For numbered affiliations see end of article.

\section{Correspondence to} Dr Sukhmeet Singh Panesar, Section of Health Services Research, Department of Medicine, Baylor College of Medicine, Houston, Texas 77030, USA; sukhmeet.panesar@ surgicalmatrix.com
\end{abstract}

Received 13 March 2015 Revised 1 September 2015 Accepted 10 November 2015 Published Online First 29 December 2015

\section{SLinked}

- http://dx.doi.org/10.1136/ bmjqs-2015-005006

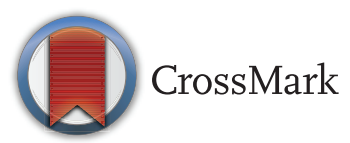

To cite: Panesar SS, deSilva D, Carson-Stevens A, et al. BMJ Qual Saf 2016:25:544-553.

\begin{abstract}
Importance Improving patient safety is at the forefront of policy and practice. While considerable progress has been made in understanding the frequency, causes and consequences of error in hospitals, less is known about the safety of primary care.
\end{abstract}

Objective We investigated how often patient safety incidents occur in primary care and how often these were associated with patient harm. Evidence review We searched 18 databases and contacted international experts to identify published and unpublished studies available between 1 January 1980 and 31 July 2014. Patient safety incidents of any type were eligible. Eligible studies were critically appraised using validated instruments and data were descriptively and narratively synthesised.

Findings Nine systematic reviews and 100 primary studies were included. Studies reported between $<1$ and 24 patient safety incidents per 100 consultations. The median from populationbased record review studies was 2-3 incidents for every 100 consultations/records reviewed. It was estimated that around $4 \%$ of these incidents may be associated with severe harm, defined as significantly impacting on a patient's well-being, including long-term physical or psychological issues or death (range $<1 \%$ to $44 \%$ of incidents). Incidents relating to diagnosis and prescribing were most likely to result in severe harm.

Conclusions and relevance Millions of people throughout the world use primary care services on any given day. This review suggests that safety incidents are relatively common, but most do not result in serious harm that reaches the patient. Diagnostic and prescribing incidents are the most likely to result in avoidable harm.

Systematic review registration This systematic review is registered with the International Prospective Register of Systematic Reviews (PROSPERO CRD42012002304).

\section{INTRODUCTION}

Health services strive to provide good quality care, but sometimes people are inadvertently harmed. ${ }^{1}$ Between 3\% and $17 \%$ of people admitted to hospital may experience a safety incident, ${ }^{1-6}$ and it is commonly reported that about $10 \%$ of hospitalised patients may experience harm. $^{7-9}$ Over the last two decades, a substantial body of work has been undertaken to understand the reasons for patient safety incidents to occur in hospitals and the effectiveness of interventions to avoid and reduce the impact of such incidents. ${ }^{10-15}$ Far less is known about the nature, causes or consequences of incidents in primary care. ${ }^{16}$ This may be due to many factors, including the assumption that primary care is safer than hospital care, because primary care is in the early stages of development in some parts of the world, and because primary care medical records may not always be easily accessible, thus making it difficult to study patient safety incidents.

An important first step in preventing harm in primary care is to understand how often patient safety incidents occur, what type of incidents occur, and what impact they have. This is particularly important given the drive for universal access, which is predicated on enhanced provision of primary care. ${ }^{17} 18$ The global drive towards primary care-based models of care has been supported by WHO in low-income and middle-income countries and economic pressures in industrialised nations. This is particularly true in the USA, which is expanding primary care through the creation of Accountable Care Organizations and Patient-Centered Medical Homes. It is important to understand how this expansion can proceed in a safe, sustainable 
manner. We were commissioned by WHO to investigate the frequency of patient safety incidents in primary care and the resulting harm in order to set the scene for deliberations on how to prevent incidents and minimise their impact.

\section{METHODS}

This systematic review of published and unpublished literature was conducted according to PRISMA guidelines. ${ }^{19}$ Our review is registered with the PROSPERO database (PROSPERO CRD42012002304). We provide a summary of our methods below. Readers are referred to full details about the methodology which is freely available online, including as part of the online supplementary material. ${ }^{20}$

\section{Inclusion and exclusion criteria}

Studies were eligible for inclusion if they were systematic reviews or primary research conducted in humans and focused on patient safety incidents in primary care. Box 1 outlines how we defined primary care, safety incidents, severity of harm and other key terms. We were interested in studies that included data about one or more of the following:

1. Number of safety incidents

2. Type of safety incidents

3. Severity of harm associated with safety incidents

Primary care varies widely between and within countries so our search strategy covered a broad range of care delivered outside hospital. ${ }^{23-29}$ However, for the purposes of this article, we focused on studies describing models of care that were comparable with US notions of primary care and incidents of commission rather than omission (see box 1 for definitions). A broader range of studies were identified on topics such as community pharmacy, but these have not been summarised here. Similarly, studies with a broad 'ambulatory care' focus were not included if these combined settings such as hospital, outpatients and primary care. Only studies with a primary care focus were included where that focus could be ascertained from the title and from the abstract.

Studies that aimed to test an intervention and collected safety data incidentally were not included, because the aim was to investigate the frequency of safety incidents and harm in routine practice, not when an intervention was undertaken.

Published and unpublished research available between 1 January 1980 and 31 July 2014 was eligible. Eligible study types were (1) systematic reviews; (2) primary studies not included in the reviews; and (3) primary studies included in the reviews only if they contained empirical data to feed into the calculation of specific estimates of harm that were not available in the reviews themselves (33 studies). Non-systematic reviews, case series or case reports were not eligible for inclusion and

\section{Box 1 Definitions of terms used in the review}

Harm - no harm, low harm, moderate harm and severe harm

Harm was defined as impairing the structure or function of the body or mind. This may include pain, nausea, psychological distress, disability or death. The criteria used in individual studies included in the review were extracted but we standardised the descriptors of harm based on methods suggested by UK's National Patient Safety Agency: ${ }^{21}$

- No harm: any patient safety incident that had the potential to cause harm but was prevented, resulting in no harm, or that ran to completion but no harm occurred

- Low harm: required extra observation or minor treatment and caused minimal harm

- Moderate harm: resulted in a moderate increase in treatment and caused significant but not permanent harm (an example would be hospitalisation)

- Severe harm: resulted in permanent harm such as disability, death or long-lasting physical or mental consequences

\section{Incidents of commission}

Incidents of commission were defined as those occurring when something was actively done incorrectly or inappropriately, such as prescribing the wrong dose of medication.

Incidents of omission

Incidents of omission were defined as those occurring when there was a lapse in the quality of care. Such incidents were outside the scope of the review.

Patient safety incidents

Patient safety incidents were defined as any unintended or unexpected incident(s) that could have or were judged to have led to patient harm. 'Patient safety incident' is an umbrella term which is used to describe a single incident or a series of incidents that occur over time. The Linnaeus taxonomy is a primary care patient safety classification system that categorises incidents into 'Process incidents' or 'Knowledge or skill incidents' and then further divides these into subcategories. ${ }^{22}$ This taxonomy was used as an initial coding framework to group studies based on their primary focus of investigation. Studies including incidents that could not be classified in this way were categorised as 'Other.'

Primary care

Primary care was defined as 'first port of call' generalist care, delivered outside hospital inpatient settings. Although in some countries primary care includes, for example, community nursing and community pharmacy in addition to family practice clinics, for the purposes of this review we used the following definition of the US primary care workforce: "...includes the specialties of family practice, general practice, general internal medicine, and general paediatrics and, for women patients, obstetricians and gynaecologists." 21 
nor were studies included in other systematic reviews that did not contain exact rates of harms for use in our calculations

\section{Search strategy and study selection}

Search terms were developed based on an international taxonomy for patient safety and previous work. ${ }^{22}{ }^{30-36}$ Our search terms are available via the online supplementary material. ${ }^{20}$

Eighteen databases containing published and unpublished literature were searched, including: African Index Medicus, African Journals Online, Bioline International, CINAHL, Embase, IndMED, HINARI, Iran MEDEX, Korean MED, Latin American and Caribbean Health Sciences, Medline, NepJOL, PsycINFO, Thai Index Medicus, WHOLIS, Google Scholar, SIGLE. The final three databases in this list include grey literature. We also searched 'The Grey Literature Report' (http://www. greylit.org/) and the Agency for Healthcare Research and Quality (AHRQ) Patient Safety Network (http:// www.psnet.arhq.gov) which is a patient safety literature clearing house. WHO invited an international panel of primary care clinicians and policy-makers to identify additional published and unpublished studies. Further material was sought using the bibliographies of identified papers and by contacting experts through WHO's six regional offices.

Where primary studies appeared in the systematic reviews that met our inclusion criteria, these were not analysed separately.

Studies identified as potentially suitable were assessed for inclusion by two independent reviewers (SSP and AC-S), with arbitration by a third reviewer (AS), if necessary. The full text of all papers was rescreened by a third reviewer (DdS) when revising the manuscript.

\section{Quality assessment}

Studies were quality appraised to assess internal and external validity ${ }^{37}$ using the Critical Appraisal Skills Programme for systematic reviews ${ }^{38}$ and the Evidence Based Library and Information Practice Critical Appraisal Checklist for epidemiological studies. ${ }^{39}$ An overall grading of the individual components was given for each study. Quality appraisal was independently carried out by two reviewers (SSP and AC-S, or $\mathrm{KMC}$ and SAS). Disagreements were resolved through discussion, with arbitration by an additional reviewer, if necessary (AS).

\section{Data extraction and synthesis}

Preliminary data were abstracted onto a customised data extraction sheet by two independent reviewers (SSP and AC-S, or KMC and SAS), with arbitration by an additional reviewer if necessary (AS). Data were then re-extracted by a third reviewer (DdS) about country of origin; study design; measurement methods; frequencies of patient safety incidents and burden of harm.
There was significant heterogeneity in the countries of origin, research methods used, type of safety incidents analysed and metrics so it was not appropriate to combine the data using meta-analysis. A descriptive and narrative synthesis of the data was undertaken. The frequency of incidents and harm were tabulated and graphed. Median incident rates were calculated based on population-based record review studies.

This review does not aim to provide a definitive summary statistic for the frequency of incidents, but rather to show the range in estimates. The rate of per 100 consultations/people/prescriptions was either drawn directly from articles or calculated from data provided in the articles. For example, if articles provided a percentage, we reframed this as a rate out of 100. Equally, if articles provided a numerator and denominator, we converted this to a denominator of 100, if appropriate. This does not allow exact comparability because the unit of measurement differed between studies (people/prescriptions/consultations), but provides a summary of broad trends.

\section{FINDINGS}

\section{Number, type and setting of studies included}

We screened 61521 articles and 109 studies met our inclusion criteria: 9 systematic reviews and 100 primary studies (see figure 1). Eighty-eight per cent of the systematic reviews $(8 / 9)$ and $12 \%$ of the primary studies $(12 / 100)$ were judged to be of high quality.

Thirty-six per cent of studies were from the USA or Canada (39/109), 39\% were from Europe (43/109), $13 \%$ were from other Organization for Economic Co-operation and Development (OECD) countries $(14 / 109)$ and $12 \%$ were from non-OECD countries (13/109). All studies focused on primary care/family practice/general practice clinics (or aggregated data drawn from these services). Most studies used record review or prescription review to measure safety incidents so they were using an epidemiological measurement approach. A minority used incident reporting systems and very few used interviews or surveys. The online supplement provides a summary of the characteristics, methods and findings of each study. ${ }^{20}$

\section{Frequency of patient safety incidents in primary care}

Fifty-nine studies (some of which were reported in more than one paper) provided an estimate of the frequency of patient safety incidents (see online supplementary table S1). Twelve studies collating 'any type of patient safety incident' reported between $<1$ and 24 incidents per 100 consultations (see figure 2). Most of the studies reporting incident rates were not of high quality, though most involved record review or review of prescriptions, coupled with the large variation in estimates; this means that we cannot confidently state the rate of patient safety incidents in primary care. However, the median of studies based 


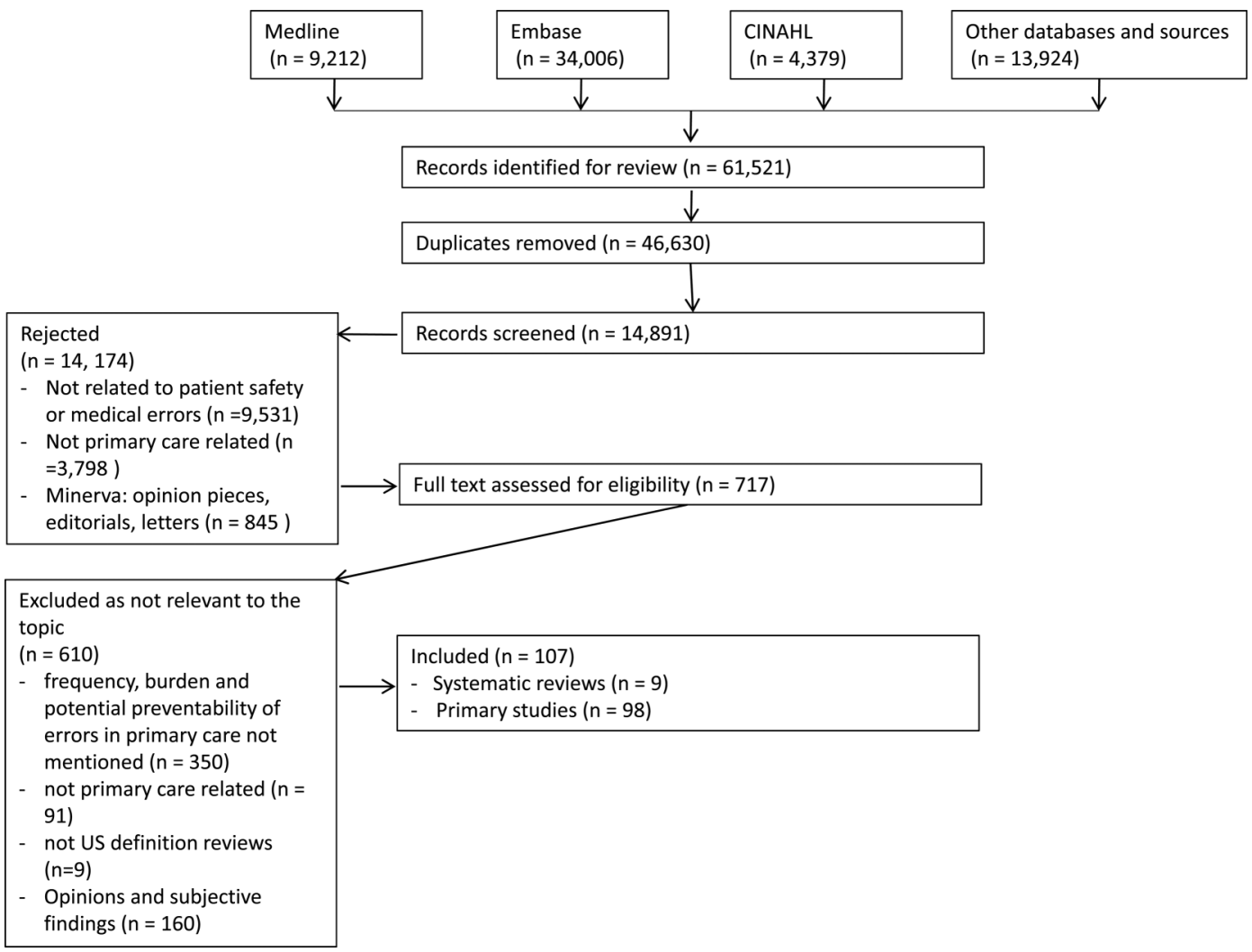

Figure 1 PRISMA diagram of studies included in the review.

on record review was 2 to 3 incidents per 100 consultations/patient records reviewed.

\section{Types of safety incidents}

Studies documenting the type of safety incidents identified that the three most common categories were: administrative and communication incidents; diagnostic incidents; and prescribing and medication management incidents. Although some studies defined 'communication issues' as safety incidents, the majority of these incidents did not result in harm. The severity of harm associated with incidents is described below.

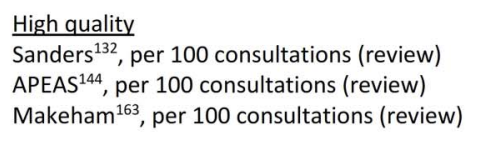

(<1)
17.9

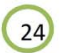

Moderate quality

Makeham $^{125}$, per 100 people

Tsang ${ }^{140}$, per 100 people

Van Dulmen ${ }^{11}$, per 100 records

de Wet ${ }^{109}$, per 100 records

McKay ${ }^{126}$, per 100 records

Smits ${ }^{136}$, per 100 records

Elder $^{112}$, per 100 consultations

$\mathrm{Gaal}^{115}$, per 100 consultations
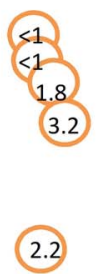

(3.2)

15)

18.6

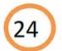

Low quality

Eggleton $^{111}$, per 100 consultations

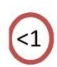

\begin{tabular}{llll}
\hline 5 & 10 & 15 & 20 \\
& Frequency of incidents per 100 consultations / records
\end{tabular}

Note: the rate per 100 consultations, records, or people is provided as specified in the text next to the study (consultations / records / people). Details of the first author are provided to allow crosschecking to the study details in the online supplement. All studies were observational unless listed as a review. The quality rating is based on validated scales.

Figure 2 Safety incidents per 100 primary care consultations/records-results from 12 studies. 
It is outside the scope of this review to comment about all the types of incidents and their relative frequency, but we provide some broad ranges to show the variation in research. For instance, the proportion of incidents relating to administrative and communication issues ranged between $6 \%$ and $67 \%$ of all incidents in individual studies. ${ }^{40-49}$ Some studies estimated that administration incidents occurred in at least $6 \%$ of patient contacts. ${ }^{50}$ Most of these incidents related to issues such as incomplete, unavailable, unclear or incorrect documentation; ${ }^{7} 225152$ inappropriate monitoring of laboratory tests; ${ }^{53}$ or insufficient communication between providers or between professionals and patients. ${ }^{54}$

Studies of incident reporting systems suggest diagnostic incidents were responsible for $4 \%$ to $45 \%$ of all reported patient safety related incidents. ${ }^{51} 54 \quad 55$ Common diagnostic incidents related to misdiagnosis or missed diagnoses.

Thirty-five studies focused explicitly on prescribing incidents, where the rate was between 1 and 90 out of 100 prescriptions issued (see online supplementary table S2). The figures were higher in studies that focused on particular subgroups, such as the elderly or those taking multiple medications. ${ }^{56-59}$ It was difficult to compare these studies because they used different measurement approaches and focused on specific patient populations.

Estimates of the rate of dispensing incidents in primary care also varied widely, from less than $2 \%$ of prescriptions $^{51}{ }^{60-64}$ to up to $65 \% .^{52}$ These variations are likely to reflect the different definitions used (such as whether or not 'not specifying the route of administration' was listed as an incident), ${ }^{65}$ study designs, ${ }^{51} 546667$ and focusing on certain subsets of patients such as those receiving psychotropic medications, ${ }^{68}$ those with polypharmacy $^{57}$ or those in care homes. ${ }^{59}$

Results varied depending on whether the studies were high or lower quality. For example, a systematic review found that retrospective studies yielded a lower estimate of adverse drug events (3\%), ${ }^{69}$ compared with prospective evaluations (10\%). ${ }^{70}$ Therefore, as with the overall rate of safety incidents, it is not possible to draw firm conclusions about the rate of consultations or people who experience diagnosis, communication or medication incidents, but we can say that these three broad categories made up the bulk of incidents recorded.

\section{Harm associated with patient safety related incidents}

Although patient safety incidents may be relatively common in primary care, many incidents did not result in actual harm. For instance, 'safety incidents' may include illegible handwriting on prescriptions, even if such incidents do not ultimately impact on well-being. The definition of 'safety incidents' often included processes rather than direct patient impacts.
As with estimates of the quantity and type of incidents in primary care, estimates of harm also varied widely. Online supplementary table S3 lists the severity of harm recorded in 33 individual studies. Many of these studies reviewed incident reports. Serious incidents may be more likely to have been reported, so these studies probably overestimated the severity of harm. Figure 3 illustrates the range of estimates from record review studies only. These types of studies are more likely to give a representative picture because they do not rely on incident reports or significant event analysis. Studies based on record review had a median estimate of $4 \%$ of incidents being associated with severe harm, defined as significantly impacting on a patient's wellbeing, including long-term physical or psychological issues or death (range $<1 \%$ to $44 \%$ ).

\section{Incidents associated with harm}

Diagnostic and medication-related incidents were most commonly associated with harm to patients. For example, one study found that $58 \%$ of reported misdiagnoses were associated with harm (severity not described). ${ }^{54}$ Between $8 \%{ }^{71}$ and $11 \%{ }^{72}$ of medication incidents were reported to result in harm (of any severity). These proportions varied depending on the population studied, research design and outcome of interest. Results also varied depending on whether the studies were high or lower quality; however, the exact proportions are perhaps less important than the fact that it was diagnostic and prescribing errors that were associated with most severe harm.

\section{DISCUSSION}

\section{Statement of principal findings}

This extensive review suggests that patient safety incidents are a relatively frequent occurrence in primary care, but that most do not result in significant harm to patients. The heterogeneity of studies means that it is not possible to provide a point estimate of the frequency of incidents, but record review studies suggested a median of around 2-3 incidents per 100 consultations/patient records reviewed. About $4 \%$ of these incidents were associated with severe harm (median of record review studies). Diagnostic and medication incidents were most likely to result in harm and most likely to result in severe harm.

\section{Strengths and limitations}

This is the most comprehensive synthesis of the evidence available about patient safety incidents in primary care. Our search strategy was broad and looked for published and unpublished studies, with particular effort made to identify research from lowincome and middle-income country settings (though few studies were found).

The review provides, for the first time, a comprehensive assessment of how common patient safety incidents are in core primary care contexts and how 


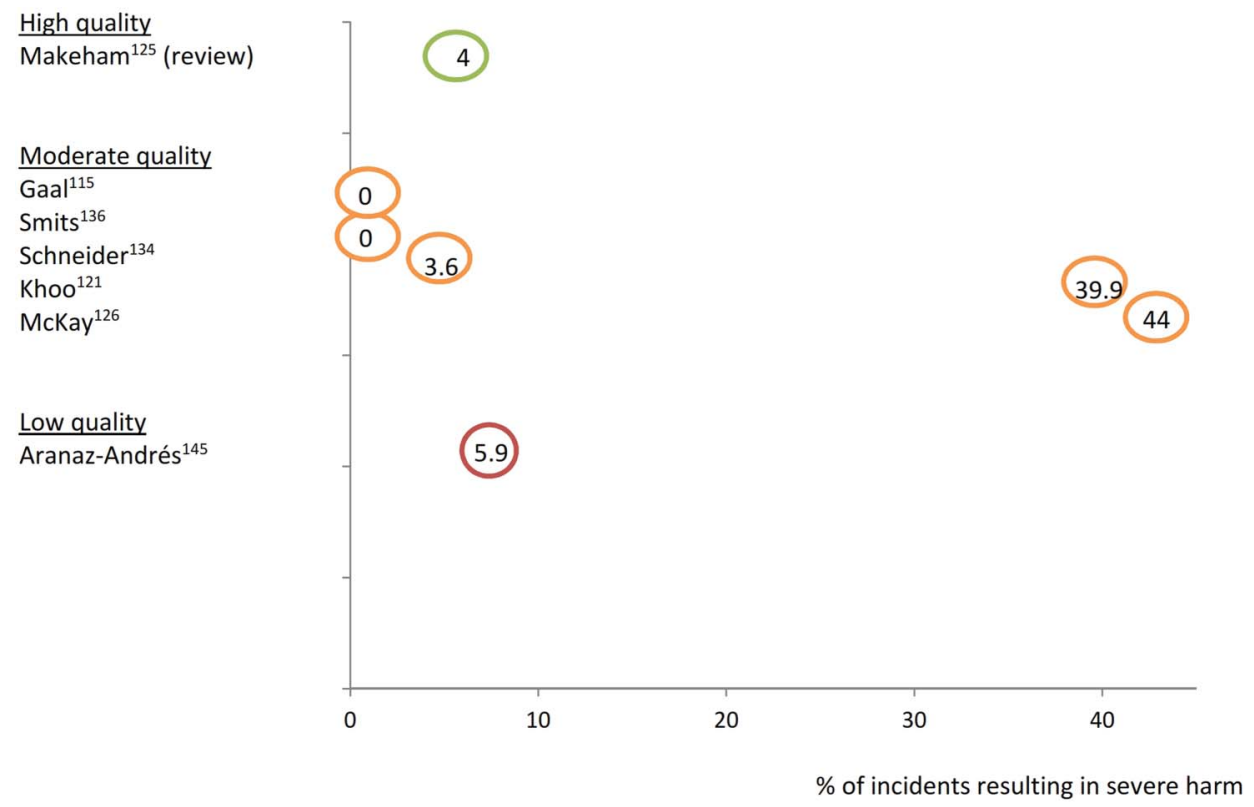

Note: Details of the first author are provided to allow cross-checking to the individual study details in the online supplement. All studies were observational unless listed as a review. The quality rating is based on validated scales.

Figure 3 Proportion of safety incidents in primary care resulting in severe harm-results from seven studies based on record review.

frequently these are associated with harm. When these estimates are considered in light of data about the high rates of use of primary care services, ${ }^{73}$ the absolute burden of iatrogenic harm may be large and may increase if primary care expansion continues in a similar fashion to the current models of care.

Understanding the epidemiology of errors in primary care contexts is crucial to baselining, understanding risk factors, and ultimately developing and evaluating strategies to reduce the risk of iatrogenic harm. We have provided a baseline from which to work.

We have also identified some key methodological insights that need to be considered when planning future epidemiological studies. Key among these are the need for multistakeholder perspectives, validated tools and longitudinal study designs in representative populations, with boosted samples in high-risk patients (eg, those with multimorbidity and/or polypharmacy).

An important issue is whether the findings of the review represent 'typical' primary care practice. To assist this we limited the review to studies focusing on primary care clinics similar to those run in a US context (rather than a wider definition of primary care as may be common in some parts of the world), but this means that other primary care contexts were excluded. It was sometimes difficult to differentiate studies for inclusion because they contained a mix of primary care and other care, or because the definition and scope of ambulatory care was not included in papers.

A major limitation is that there is no widely used standardised taxonomy for classifying incidents in primary care settings. ${ }^{8} 7475$ This means that studies defined and measured incidents differently, resulting in variations in the estimated proportion of incidents and harms. Higher quality studies, those with a broad population focus, and those based on record review were more likely to have lower estimates of the frequency and severity of harm. Relationships between country, data quality, setting and severe harm deserve further attention.

Most studies used a single method to assess the frequency of incidents, rather than a triangulation of approaches. This may underestimate the frequency of incidents. The primary care record systems used to record incidents may also be open to coding errors.

As with all systematic reviews, publication bias may be present, whereby certain types of studies may be more likely to be published. We sought to address this by searching extensively for unpublished literature and by sense-checking findings with international experts. The large variability of findings suggests that our results were not unduly tarnished by only the highest levels of incidents or harms being reported. The variability of estimates remained regardless of whether studies were rated as high or low quality.

Our graphical representation of the severity of harm is based on studies that reviewed records, rather than relying on incident reports. This is because incident reports may be less likely to capture incidents that have low severity and people may be more likely to report some types of incidents than others. Studies of malpractice claims may be particularly open to bias so we excluded these when reporting median rates.

Recommendations for policy, practice and future research Patient safety is high on the policy radar when developing and rolling out new models of primary care (eg, Patient-Centered Medical Homes). But these 
'solutions' can introduce new risks which need to be proactively identified. For example, health information technology has been seen as an important solution to enhancing safety, but it is now appreciated that such technology can also introduce some new risks. ${ }^{76}$ Having standardised methods to identify and quantify these risks is essential.

Key implications of this review include the need to develop a standardised set of definitions of core terminology, the need to promote mixed-methods evaluations that triangulate different sources of evidence, and a particular focus on diagnostic and medication errors, which appear to be most frequently associated with severe patient harm. There is also a need to better identify those at greatest risk of experiencing patient safety incidents and the nature of the incidents that occur, because such insights will be crucial to developing interventions to decrease the burden of iatrogenic harm.

A standardised taxonomy for classifying incidents and harm would allow comparisons across settings, countries and over time. Longitudinal, multimethods investigations would provide more insight into the extent of harm associated with different types of error. More in-depth analysis into particular areas of high risk is warranted, in particular people with multiple long-term conditions and associated polypharmacy. The paucity of evidence about low-income and middle-income countries highlights the need for more work to understand the nature of incidents and the opportunities for prevention in these resource-scarce contexts.

The estimated proportion of patient safety incidents in primary care is generally lower than the estimated $10 \%$ of people who experience events in hospital, ${ }^{7}$ but primary care and hospital encounters are not easily comparable because hospitalised patients experience multiple clinical encounters during a single admission. Furthermore, the overall volume of people using primary care is substantially higher than those using hospital services in many parts of the world, so even if incidents occur in a lower proportion of visits, this translates into a considerable burden of potential harm, though most is not severe. ${ }^{77}$ However, incidents occur in all care settings so this finding is only useful if it prompts policy-makers and clinicians to do something about it. ${ }^{78}$ Better prediction tools and more experimental studies are needed to understand which incidents we can avoid, and how best to do so.

It is important to consider whether adverse drug events and similar events are 'incidents' if the medication was correctly prescribed, dispensed and monitored. In this review, all incidents were counted, as it was not possible to distinguish 'correct' prescribing from individual studies. However, it may be more useful to consider whether incidents are preventable versus a result of proper care. Research has attempted to determine what proportion of safety incidents may be preventable. Most studies of this type relate to prescribing and medication management inci$\begin{array}{llllll}\text { dents, }^{7} & 53 & 68 & 79 & 80 & \text { and use observational }\end{array}$ cross-sectional designs, so it can be challenging to interpret the estimates. A small number of more robust before-and-after studies and randomised controlled trials have found that up to half of all incidents may be preventable using interventions such as pharmacist-led medication review, computerised physician order entry and computerised decision support systems, error alert systems and education of professionals. ${ }^{65} 81-88$

\section{Conclusions}

Primary care services are expanding globally, providing a first port of call to millions of people every day. ${ }^{18}$ Universal access to healthcare remains firmly on the agenda of policy-makers, however, these services are not without potential harms. This review has suggested major gaps in the evidence base which now need to be filled. WHO's forthcoming road map on Safer Primary Care for All will explore the most effective ways to prevent incidents, particularly those most likely to cause serious harm.

To further support this journey, there is a need for researchers to use existing well developed definitions, taxonomies and tools, such as the National Patient Safety Agency (NPSA) definition and the Linnaeus taxonomy, ${ }^{21}{ }^{89}$ to allow greater comparability between studies and research contexts. There is also a need for better quality epidemiological studies, but the review shows that focusing on diagnostic and prescribing errors-which are the most frequent and hence important sources of significant iatrogenic harm —needs to be a priority for research and policy. ${ }^{90-92}$

Author affiliations

${ }^{1}$ Section of Health Services Research, Department of Medicine, Baylor College of Medicine, Houston, Texas, USA

${ }^{2}$ The Evidence Centre, London, UK

${ }^{3}$ Primary Care Patient Safety Research Group, Cochrane

Institute of Primary Care and Public Health; School of Nursing and Midwifery Studies, Cardiff University, Cardiff, UK

${ }^{4}$ Centre for Medical Informatics, Usher Institute of Population

Health Sciences and Informatics, University of Edinburgh,

Edinburgh, UK

${ }^{5}$ Wolfson Research Institute, Durham University, Durham, UK

${ }^{6}$ MRC Epidemiology Unit, Institute of Metabolic Science,

Addenbrooke's Hospital, Cambridge, UK

${ }^{7}$ Institute for Health and Human Development, University of

East London, London, UK

${ }^{8}$ Patient Safety Programme, WHO, Geneva, Switzerland

${ }^{9}$ Department of Surgery and Cancer, Imperial College London, London, UK

${ }^{10}$ Division of General Medicine and Primary Care, Department of Medicine, Brigham and Women's Hospital, Boston, MA, USA

Twitter Follow Sukhmeet Panesar at@sukhmeetpanesar and David Bates at@dbatessafety

Collaborators WHO's Safer Primary Care Expert Working Group: Carlos Aibar, Hamad Al-Bulushi, Buthaina Al-Mudaf, Hisham Aljadhey, Fawzi Amin, Anthony Avery, Pierre Barker, Jean Brami, Perpetual Chikobvu, Aneez Esmail, John Hickner, Neil Houston, Tawfik Khoja, Maaike Langelaan, Mondher 
Letaief, Chaojie Liu, Rajan Madhok, Meredith Makeham, Philippe Michel, Yakoub Neyaz, Ludovic Reveiz Herault, Gurdev Singh, Ranjit Singh, Andreas Soennichsen, Nicole Spieker, Hans Trier, Amardeep Thind, Nana Twum-Danso, Wim Verstappen, Katharine Wallis, Stuart Whittaker, Benedetta Allegranzi, Edward Kelley, Angela Diane Lashoher, Shamsuzzoha Babar Syed, Antonio Villafaina, Yonatan Yohannes, Kevin Wang, Maria-Carmen Audera-Lopez, Marie-Paule Kieny.

Contributors AS oversaw all aspects of the work. SSP, AC-S, KMC, SAS, SPS and SJ were responsible for acquisition of data and drafting earlier versions of the manuscript. DdS extracted data, undertook the analysis and redrafted the manuscript. GN, IL, LJD, DWB and AS made substantial contributions to the design of the study and revised it critically. All authors reviewed the final manuscript. Members of the Safer Primary Care Expert Working Group discussed early drafts of the review at the expert consultation and commented on the final version.

\section{Funding WHO.}

Competing interests IL works for WHO. LJD is the WHO Special Envoy for patient safety. DWB is external advisor for patient safety research, WHO. All authors have completed the ICMJE uniform disclosure form at www.icmje.org/ coi_disclosure.pdf and declare funding by the Patient Safety Programme, WHO, Geneva, Switzerland. The authors declared no financial relationships with any organisations that might have an interest in the submitted work in the previous 3 years and no other relationships or activities that could appear to have influenced the submitted work.

Provenance and peer review Not commissioned; externally peer reviewed.

\section{REFERENCES}

1 Landrigan CP, Parry GJ, Bones CB, et al. Temporal trends in rates of patient harm resulting from medical care. $N$ Engl J Med 2010;363:2124-34.

2 Baker GR, Norton PG, Flintoft V, et al. The Canadian adverse events study: the incidence of adverse events among hospital patients in Canada. CMAJ 2004;170:1678-86.

3 Brennan TA, Leape LL, Laird NM, et al. Incidence of adverse events and negligence in hospitalised patients: results of the Harvard Medical Practice Study I. 1991. Qual Saf Health Care 2004;13:145-51.

4 Davis P, Lay-Yee R, Briant R, et al. Adverse events in New Zealand public hospitals. I. Occurrence and impact. N Z Med J 2002;115:U271.

5 Schioler T, Lipczak H, Pedersen BL, et al. Incidence of adverse events in hospitals. A retrospective study of medical records. Ugeskr Laeger 2001;163:5370-8.

6 Thomas EJ, Studdert DM, Burstin HR, et al. Incidence and types of adverse events and negligent care in Utah and Colorado. Med Care 2000;38:261-71.

7 Vincent C, Neale G, Woloshynowych M. Adverse events in British hospitals: preliminary retrospective record review. BMJ 2001;322:517-19. Erratum in: BMJ 2001;322(7299):1395

8 Makeham M, Dovey S, Runciman W, et al. Methods and measures used in primary care patient safety research, 2008. http://www.who.int/patientsafety/research/methods_measures/ makeham_dovey_full.pdf (ccessed 1 Jan 2015).

9 Kohn LT, Corrigan JM, Donaldson MS. To err is human: building a safer health system. Washington DC: National Academy Press, 2000.

10 Clinton HR, Obama B. Making patient safety the centerpiece of medical liability reform. N Engl J Med 2006;354:2205-8.
11 Leape LL, Brennan TA, Laird NM, et al. The nature of adverse events in hospitalised patients: Results from the Harvard Medical Practice Study II. N Engl J Med 1991;324:377-84.

12 Bates DW, Cullen DJ, Laird N, et al. Incidence of adverse drug events and potential adverse drug events. Implications for prevention. ADE Prevention Study Group. JAMA 1995;274:29-34.

13 World Health Organization. Clean Care is Safer Care. http:// www.who.int/gpsc/en/index.html. (accessed 1 Jan 2015).

14 World Health Organization. Safe Surgery Saves Lives. http://www. who.int/patientsafety/safesurgery/en/ (accessed 1 Jan 2015).

15 Haynes AB, Weiser TG, Berry WR, et al, Safe Surgery Saves Lives Study Group. A surgical safety checklist to reduce morbidity and mortality in a global population. N Engl J Med 2009;360:491-9.

16 World Health Organization. Safer Primary care-A Global Challenge. http://www.who.int/patientsafety/summary_report_ of_primary_care_consultation.pdf. (accessed 1 Jan 2015).

17 World Health Organization. The World Health Report 2008Primary Health Care (Now More than Ever). http://www.who. int/whr/2008/en/index.html. (accessed 22 Sep 2014).

18 Sheikh A, Panesar SS, Larizgoitia I, et al. Safer Primary care for All-A Global Imperative. Lancet Global Health 2013;1: e182-3.

19 Moher D, Liberati A, Tetzlaff J, et al. The PRISMA Group. Preferred Reporting Items for Systematic Reviews and Meta-Analyses: The PRISMA Statement. PLoS Med 2009;6: e1000097.

20 Panesar SS, Carson-Stevens A, Salvilla SA, et al. Estimating the frequency of errors and the global burden from iatrogenic harm in primary care: protocol for a systematic review and meta-analysis (accepted April 2012) http://www.crd.york.ac.uk/ PROSPEROFILES/2304_PROTOCOL_20120323.pdf. (accessed 1 Jan 2015).

21 National Patient Safety Agency. Seven Steps to Patient Safety. 2004. http://www.nrls.npsa.nhs.uk/resources/collections/ seven-steps-to-patient-safety/?entryid45 $=59787$. (accessed 1 Jan 2015).

22 Singh R, Singh A, Singh S, et al. Creating a Common Vision for all Stakeholders to Make Healthcare Safer with Interactive Visual Modeling. Special Issue on Soft Computing, Simulation, and Web centric Computing on Selected Papers from NASTEC 2009. Int J Adv Intel Pradigms (IJAIP). 2011;3.

23 Declaration of Alma-Ata. International Conference on Primary Health Care.. Alma-Ata, USSR: World Health Organization, 1978. http://www.who.int/publications/almaata_declaration_en. pdf (accessed 1 Jan 2015).

24 Institute of Medicine. Primary care: America's Health in a New Era. http://www.nap.edu/openbook.php?record_ $\mathrm{id}=5152 \&$ page $=27$ (accessed 1 Jan 2015).

25 Starfield B. Basic concepts in population health and health care. J Epidemiol Community Health 2001;55:452-4.

26 WHO. Health Systems Strengthening Glossary. http://www. who.int/healthsystems/hss_glossary/en/index $8 . h t m l \# 8$. (accessed 1 Jan 2015).

27 Hospital Report Research Collaborative. New measures of ambulatory care performance in Ontario. 2006. http://www. hospitalreport.ca/downloads/otherreports/SNAPSHOT_ REPORT_Amb_FINAL.pdf (accessed 1 Jan 2015).

28 World Health Organization. More than words. Conceptual Framework for the International Classification for Patient Safety. 2009. http://www.who.int/patientsafety/implementation/ taxonomy/icps_technical_report_en.pdf. (accessed 1 Jan 2015). 
29 World Bank. How we classify countries. 2012. http://data. worldbank.org/about/country-classifications (accessed 1 Jan 2015).

30 Kingston-Reichers J, Ospina M, Jonsson E, et al. Patient safety in primary care. Edmonton, AB: Canadian Patient Safety Institute and BC Patient Safety and Quality Council, 2010.

31 Makeham M, Dovey S, Runciman W, et al. Methods and measures used in primary care patient safety research. http:// www.who.int/patientsafety/research/methods_measures/ primary_care_ps_research/en/index.html (accessed 1 Jan 2015).

32 Tanon AA, Champagne F, Contandriopoulos AP, et al. Patient safety and systematic reviews: finding papers indexed in MEDLINE,EMBASE and CINAHL. Qual Saf Health Care 2010;19:452-61.

33 Pearson A, Aromataris A. Patient Safety Primary care: a review of the literature. Australian Commission on Safety and Quality in healthcare. http://www.safetyandquality.gov.au/wp-content/ uploads/2009/01/Patient-Safety-in-Primary-Health-Care-AReview-of-the-Literature-2009.pdf (accessed 1 Jan 2015).

34 Anesthesia Patient Safety Foundation. http://www.apsf.org/ about_safety.php. (accessed 1 Jan 2015).

35 Dovey SM, Meyers DS, Phillips RL, Jr, et al. A preliminary taxonomy of medical errors in family practice. Qual Saf Health Care 2002;11:233-8.

36 Bindman Andrew B, Majeed Azeem. Organisation of primary care in the United States. BMJ 2003;326:631.

37 Cochrane Group. Assessing risk of bias in included studies. 2011. http://handbook.cochrane.org/chapter_8/8_assessing risk_of_bias_in_included_studies.htm. (accessed 1 Jan 2015).

38 Solutions for Public Health. Critical Appraisal Skills Programme. 2007. http://www.casp-uk.net/\#!casptools-checklists/c18f8. (accessed 1 Jan 2015).

39 Glynn L. EBLIP Critical Appraisal Checklist. 2006. http:// ebltoolkit.pbworks.com/f/EBLCriticalAppraisalChecklist.pdf. (accessed 1 Jan 2015).

40 Cox SJ, Holden JD. A retrospective review of significant events reported in one district in 2004-2005. Br J Gen Pract 2007;57:732-6.

41 Hansen LB, Fernald D, Araya-Guerra R, et al. Pharmacy clarification of prescriptions ordered in primary care: a report from the applied strategies for improving patient safety (ASIPS) collaborative. J Am Board Fam Med 2006;19:24-30.

42 McKay J, Bradley N, Lough M, et al. A review of significant events analysed in general practice: implications for the quality and safety of patient care. BMC Fam Pract 2009;10:61.

43 Diamond MR, Kamien M, Sim MG, et al. A critical incident study of general practice trainees in their basic general practice term. Med J Aust 1995;162:321-4.

44 Elder NC, Vonder Meulen M, Cassedy A. The identification of medical errors by family physicians during outpatient visits. Ann Fam Med 2004;2:125-9.

45 Rosser W, Dovey S, Bordman R, et al. Medical errors in primary care: results of an international study of family practice. Can Fam Physician 2005;51:386-7.

46 Fit KE, Burkiewicz JS, Sweeney BL. PDA-based documentation of medication interventions in an ambulatory care setting. $J$ Pharm Technol 2007;23:9-16.

47 Bhasale AL, Miller GC, Reid SE, et al. Analysing potential harm in Australian general practice: an incident-monitoring study. Med J Aust 1998;169:73-6.

48 Kuzel AJ, Woolf SH, Gilchrist VJ, et al. Patient reports of preventable problems and harms in primary health care. Ann Fam Med 2004;2:333-40.
49 Hickner J, Graham DG, Elder NC, et al. Testing process errors and their harms and consequences reported from family medicine practices: a study of the American Academy of Family Physicians National Research Network. Qual Saf Health Care 2008;17:194-200.

50 Sayers YM, Armstrong P, Hanley K. Prescribing errors in general practice: a prospective study. Eur J Gen Pract 2009;15:81-3.

51 Teagarden JR. Dispensing error rate in a highly-automated mail-service pharmacy practice. Pharmacotherapy 2005;25:1629-35.

52 Teinila T, Gronroos V, Airaksinen M. Survey of dispensing error practices in community pharmacies in Finland: a nationwide study. J Am Pharm Assoc 2009;49:604-10.

53 Mitchell ED, Rubin G, Macleod U. Understanding diagnosis of lung cancer in primary care: qualitative synthesis of significant event audit reports. Br J Gen Pract 2013;63:e37-46.

54 Hoffmann B, Beyer M, Rohe J, et al. "Every error counts": a web-based incident reporting and learning system for general practice. Qual Saf Health Care 2008;17:307-12.

55 Ilboudo TP, Chou YJ, Huang N. Assessment of providers' referral decisions in rural Burkina Faso: a retrospective analysis of medical records. BMC Health Serv Re.s 2012;12:54.

56 Stewart AL, Lynch KJ. Identifying discrepancies in electronic medical records through pharmacist medication reconciliation. J Am Pharm Assoc 2012;52:59-68.

57 Bradley MC, Fahey T, Cahir C, et al. Potentially inappropriate prescribing and cost outcomes for older people: a cross-sectional study using the Northern Ireland Enhanced Prescribing Database. Eur J Clin Pharmacol 2012;68: 1425-33.

58 Taylor LK, Kawasumi Y, Bartlett G, et al. Inappropriate prescribing practices: the challenge and opportunity for patient safety. Health Q 2005;8 Spec No:81-85.

59 Van Der Hooft CS, Jong GW, Dieleman JP, et al. Inappropriate drug prescribing in older adults: the updated 2002 Beers criteria-a population-based cohort study. Br J Clin Pharmacol 2005;60:137-44.

60 Chua SS, Wong ICK, Edmondson H, et al. A feasibility study for recording of dispensing errors and 'near misses' in four UK primary care pharmacies. Drug Safety 2003;26:803-13.

61 Flynn EA. Medication dispensing errors in community pharmacies: a nationwide study. Proc Hum Fact Ergonom Soc 2002;46:1448-51.

62 Flynn EA. National observational study of prescription dispensing accuracy and safety in 50 pharmacies. J Am Pharm Assoc 2003;43:191-200.

63 Kayne S. Negligence and the pharmacist. Part 3. Dispensing and prescribing errors. Pharm J 1996;257:32-5.

64 Hoxsie DM. Analysis of community pharmacy workflow processes in preventing dispensing errors. J Pharm Pract 2006;19:124-30.

65 Al Khaja KAJ, Damanhori AHH, Al-Ansari TM, et al. Topical corticosteroids in infants: prescribing pattern and prescribing errors in Bahrain. Pharm World Sci 2007;29:395-9.

66 James KL, Barlow D, McArtney R, et al. Incidence, type and causes of dispensing errors: a review of the literature. Int $\mathrm{J}$ Pharm Pract 2009;17:9-30.

67 Ashcroft DM, Quinlan P, Blenkinsopp A. Prospective study of the incidence, nature and causes of dispensing errors in community pharmacies. Pharmacoepidemiol Drug Saf 2005;14:327-32. 
68 Guthrie B, McCowan C, Davey P, et al. High risk prescribing in primary care patients particularly vulnerable to adverse drug events: cross sectional population database analysis in Scottish general practice. BMJ (Overseas \& Retired Doctors Edition) 2011;342:1406-7.

69 Makeham MA, Kidd MR, Saltman DC, et al. The Threats to Australian Patient Safety (TAPS) study: incidence of reported errors in general practice. Med J Aust 2006;185:95-8.

70 Martinez Sanchez A, Campos RM. Detection of prescribing related problems at the community pharmacy. Int J Clin Pharm 2011;33:66-9.

71 van Dulmen SA, Tacken MA, Staal JB, et al. Patient safety in primary allied health care: what can we learn from incidents in a Dutch exploratory cohort study? Med Care 2011;49:1089-96.

72 Hickner J, Zafar A, Kuo GM, et al. Field test results of a new ambulatory care Medication Error and Adverse Drug Event Reporting System-MEADERS. Ann Fam Med 2010;8:517-25.

73 NHS England. Improving general practice-a call to action. http://www.england.nhs.uk/ourwork/qual-clin-lead/calltoaction/ igp-cta/. (accessed 1 Jan 2015).

74 Elder NC, Dovey SM. Classification of medical errors and preventable adverse events in primary care: a synthesis of the literature. J Fam Pract 2002;51:927-32.

75 Sandars J, Esmail A. The frequency and nature of medical error in primary care: understanding the diversity across studies. Fam Pract 2003;20:231-6.

76 Institute of Medicine. Health IT and Patient Safety: Building Safer Systems for Better Care. 2011. http://www.iom.edu/ Reports/2011/Health-IT-and-Patient-Safety-Building-SaferSystems-for-Better-Care.aspx. (accessed 1 Jan 2015).

77 Sheikh A, Panesar SS, Larizgoitia A, et al. Safer primary care for all: a global imperative. Lancet Global Health 2013;1:e182-3.

78 Cresswell K, Panesar SS, Salvilla SA, et al. Global research priorities to better understand the burden of iatrogenic harm in primary care: an international Delphi exercise. PLoS Med 2013;10:e1001554.

79 Al Khaja KA, Sequeira RP, Damanhori AH. Medication prescribing errors pertaining to cardiovascular/antidiabetic medications: a prescription audit in primary care. Fundam Clin Pharmacol . 2012;26:410-17.

80 Olaniyan JO, Ghaleb M, Dhillon S, et al. Safety of medication use in primary care. Int J Pharm Pract 2015;23:3-20. http://dx. doi.org/10.1111/ijpp.12120
81 Kane-Gill SL, Van JB, Handler SM. Adverse drug reactions in hospital and ambulatory care settings identified using a large administrative database. Ann Pharmacother 2010;44:983-94.

82 Zavaleta-Bustos M, Castro-Pastrana LI, Reyes-Hernandez I, et al. Prescription errors in a primary care university unit: Urgency of pharmaceutical care in Mexico.

83 Hider P, Lay-Yee R, Davis P, et al. Monitoring the quality of primary care: Use of hospital-based audit studies. In J Risk Saf Med 2005;17:81-9.

84 Krska J, Cromarty JA, Arris F, et al. Pharmacist-led medication review in patients over 65: a randomized, controlled trial in primary care. Age Ageing 200;30:205-11.

85 Granas AG, Berg C, Hjellvik V, et al. Evaluating categorisation and clinical relevance of drug-related problems in medication reviews. Pharm World Sci 2010;32: 394-403.

86 Tamblyn R, Huang A, Taylor L, et al. A randomized trial of the effectiveness of on-demand versus computer-triggered drug decision support in primary care. J Am Med Informatics Assoc 2008;15:430-9.

87 Palen TE, Raebel M, Lyons E, et al. Evaluation of laboratory monitoring alerts within a computerized physician order entry system for medication orders. Am J Managed Care 2006;12:389-96.

88 Batuwitage BT, Kingham JGC, Morgan NE, et al. Inappropriate prescribing of proton pump inhibitors in primary care. Postgrad Med J 2007;83:66-8.

89 Makeham MA, Dovey SM, County M, et al. An international taxonomy for errors in general practice: a pilot study. Med J Aust 2002;177:68-72.

90 Cresswell KM, Panesar SS, Salvilla SA, et al. Global research priorities to better understand the burden of iatrogenic harm in primary care: an international delphi exercise. PLoS Med 2013;10:e1001554.

91 Avery AJ, Rodgers S, Cantrill JA, et al. A pharmacist-led information technology intervention for medication errors (PINCER): a multicentre, cluster randomised, controlled trial and cost-effectiveness analysis. Lancet 2012;379: 1310-19.

92 Honigman B, Lee J, Rothschild J, et al. Using computerized data to identify adverse drug events in outpatients. J Am Med Inform Assoc 2001;8:254-66. 